\title{
González Prada y la prosa española
}

$F^{N}$ las tres décadas transcurridas desde su muerte, ha aumentado grandemente la importancia de Manuel González Prada en la historia de las letras y del pensamiento en Hispanoamérica. Sus prosas $\mathrm{y}$ versos, muchos inéditos durante largos años, se han publicado en ediciones dispersas, y ahora se imprimen sus obras completas en Lima, su ciudad natal. ${ }^{1}$ Existen varias antologías de la prosa y una de la poesía del gran peruano. ${ }^{2}$ Carlos García Prada en 1940 publicó un excelente ensayo-estudio sobre su poesía que sirve de introducción a la antología de sus versos. Pero ningún crítico, que sepamos, ha hecho un análisis detenido de la prosa de González Prada. ${ }^{3}$ Por tanto, nuestro propósito aquí es un examen de las características de su prosa y una estimación del lugar que ocupa dentro del proceso histórico de la prosa española.

El hecho de que González Prada comenzara su carrera durante los años de reorganización social hispanoamericana (1860-1890) determina, en gran parte, su situación como prosista. Debe colocarse en un punto equidistante entre los grandes ensayistas-precursores de la primera generación romántica, como Juan María Gutiérrez, Sarmiento, Mitre y los del Modernismo. ${ }^{4}$ Con mayor preparación científica, es menos ingenuo que los románticos. En su temática huye de lo abstracto y universal hacia lo social y concreto. Pero su insistencia en una visión positiva del mundo le aparta definitivamente del grupo de ensayistas finiseculares. Si tiene semejantes en el mundo hispano serían del tipo de los jefes liberales de la generación del '68 en España, Sanz del Río y Giner de los Ríos. Prada no era, como ellos, krausista, pero compartía sus teorías sociales: rechazo de la filosofía ortodoxa y eclesiástica, establecimiento de la educación secular, oposición al militarismo, insistencia en. la re- 
forma política y económica; en fin, la plena entrada de España (e Hispanoamérica) en las corrientes socio-económicas de la Europa moderna.

De la generación de sus contemporáneos en España pueden compararse Prada y Joaquín Costa. Como el español, durante algún tiempo el peruano en el rôle de reformador y jefe del partido radical de su país, luchó por una educación menos teórica y más práctica que desarrollara al hombre entero, y fué además el primero en señalar los grandes problemas sociales de su patria. Pero difiere de Costa porque, al contrario del español, no presenta un detallado programa constructivo, ni sugiere soluciones específicas. Huelga decir que González Prada dista mucho de ensayistas del tipo de Ganivet y Unamuno. Estos, en su análisis de España, además de examinar los factores objetivos, toman un punto de vista subjetivo y admiten valores psicológicos, vitales. Reconocen el error de la disección racionalista de tradición cartesiana. No así Prada; a lo menos no en las ideas que expone en sus ensayos. En su prosa se acentúa la actitud de la ciencia positiva, y no hay ningún asomo de ciencia teórica. Se notan diferencias radicales, también, entre Prada y su gran contemporáneo ecuatoriano, Juan Montalvo. Ambos son ciudadanos "siempre en lucha contra malos gobernantes y malos sacerdotes", " pero Montalvo, católico, tradicionalista, anti-positivista, anti-darwinista, anti-naturalista, ideológicamente es antipodal al peruano. ${ }^{6}$

La figura de González Prada como prosista de ideas es única en el Perú de su tiempo. Conocedor de las corrientes intelectuales dè la Europa contemporánea, hombre de una cultura esencialmente literaria, creyente en la superioridad del método científico para resolver los problemas de la vida social y deseoso de ver un gran aumento en la libertad intelectual y física del individuo, Prada se impacienta hondamente ante la escena nacional. Nadie lucha por estos ideales en el Perú, país agotado y desorganizado, habitado por un pueblo de espíritu decaído a raíz de la derrota sufrida en la guerra del Pacífico. Todos se conforman con el status quo, con la inacción, y lo tradicional en literatura, en política, en religión. En 1885 ya no puede contenerse más, y se lanza brioso a la vocación de regenerador cívico e intelectual: su tarea será didáctica, pero para ser eficaz y producente, su prosa, además, de enseñar, tendrá que galvanizar y estimular a la acción. Pero nunca llega a ser grandilocuente; 
su actitud es más la del autor que emplea la prosa afectiva con el propósito de inducir y conmover, no abrumar a sus lectores. Fundamentalmente, González Prada es un moralista indignado: no del tipo tradicional sino individualista, como el francés Jean Marie Guyau, con quien tiene numerosas afinidades ideológicas. Se opone a la sonora elocuencia de Emilio Castelar y otros tribunos contemporáneos en España, a quienes aplica la siguiente conocida figura: "[Castelar] el tambor mayor del siglo xix [que] marcha presidiendo el bullicioso batallón de los hombres locuaces, de todos los inagotables habladores que hablan i hablan por el solo prurito de hablar." 7 No: la prosa de González Prada será elocuente porque en ella "todo fluye i se desliza con llaneza, desenfado i soltura." s Su prosa será elocuente porque expresará clara y concisamente las ideas del autor, porque su forma será variable pero harmoniosa, de modo que no canse al lector $u$ oyente. No es exagerado afirmar que por toda su prosa se transluce un intento de hablar al oyente o lector con el propósito de agitar y convencer por medio de la razón pura más que por los acostumbrados recursos de la retórica. Esta sencilla cualidad oratoria se notará fácilmente al leer en voz alta un trozo de su prosa escogido al azar; muchas veces aun meros artículos periodísticos revelan su empaque tribunicio.

Si aceptamos la observación de Medardo Vitier que el ensayo hispanoamericano, como género legítimo, no se desarrolla plenamente hasta fines del siglo XIX, ${ }^{9}$ entonces González Prada, además de prosista notable, viene a ser uno de nuestros primeros ensayistas también. Su prosa consiste en un gran número de ensayos, discursos, conferencias, artículos periodísticos y uno que otro estudio monográfico (literario o biográfico). Los géneros que él prefiere, como se ve, son los que se prestan a la prosa activa, discursiva, didáctica. Es notable en su obra la constante evasión de lo personal; en el proceso total de sus escritos hay sólo tres o cuatro en que se asoman sus afectos íntimos. Pero no se crea por esto que el tono didáctico predomina en su prosa: Prada no expone sus ideas y nociones a manera de tratadista, rigurosamente ordenadas y sistematizadas sino, como demostraremos, con tin dinamismo y estilo flexible que faltan en los textos de enseñanza. Pueden muy bien aplicarse a estos ensayos los términos que emplea Vitier para el género, son "meditaciones aladas."'10 
Conviene ahora examinar con mayor detención los elementos formales de la prosa de González Prada. Durante los primeros años de su militancia cívica e intelectual (1885-c. 1900) cuando se dirige a un público instruído, los discursos, conferencias y ensayos se caracterizan por referencias cultas, mayor extensión y buen tejido lógico. ${ }^{11}$ Ya se vislumbran en este período, sin embargo, los rasgos estructurales que en adelante caracterizarán sus escritos. Con una que otra excepción el siguiente esquema indica la estructura general de los discursos, ensayos y los más de sus artículos periodísticos:

1. Plantea el tema principal (censura de la initación intelectual, de la política tradicional, de la educación católica, etc.), ilustrándola con una figura deslumbradora: metáfora, símile, personificación.

2. Discurre didácticamente sobre el tema, sacando ejemplos de varios campos del conocimiento: literatura, historia, ciencia. Salpica si discusión con otras figuras para mantener el interés del lector u oyente.

3. Hacia el fin del escrito, a modo de resumen o reiteración del temá principal, hay unas veces un arrebato o invocación, otras, una metáfora o figura terminal.

Después de dejar el movimiento radical (1902) y comenzar su apostolado solitario, cambia forzosamente la naturaleza de su obra. Impedidos sus discursos por el gobierno, Prada no puede contener su. crítica social y política. Por tanto, valiéndose del único vehículo vulgarizador que le quedaba - los pequeños periódicos obreroscomenta acerbamente temas de actualidad. Reduce el tema a sus aspectos más sencillos, deja en gran parte la prosa elocuente de su primer período y simplifica el vocabulario. Debido a estas razones y a su variada lectura, su rechazo de toda sistematización rígida del pensamiento y su preferencia por los problemas concretos, en muchos casos sus escritos ostentan un carácter fragmentario. Aún estos artículos, sin embargo, por lo general conservan la forma esquemática que ya indicamos. ${ }^{12}$ Debe notarse, además, que Prada nunca dejó de componer ensayos del primer tipo. ${ }^{13}$

Cabe ahora, a fin de ilustrar los elementos formales que hemos señalado, citar unos ejemplos típicos. Como disponemos de un espacio limitado analizaremos, de su obra total, una conferencia, 
un ensayo y dos o tres artículos periodísticos. Además, quien se interese, al leer los escritos de Prada, pronto notará los perfiles de su armazón estructural.

En la "Conferencia en el Ateneo de Lima" (1886) 14 Prada censura la imitación intelectual peruana $\mathrm{y}$ expone sus propios ideales literarios y culturales. Plantea el tema con una metáfora imponente: "Si los hombres de jenio son cordilleras nevadas, los imitadores no pasan de riachuelos alimentados con el deshielo de la cumbre."15 Siguen páginas de análisis literario ilustrado por ejemplos históricos, figuras, metáforas y salpicado por aforismos a veces metafóricos: "El buen gusto helénico no abunda en Alenania; si las obras de los griegos parecen un ordenado parque inglés, las obras de los alemanes semejan un bosque virjen de América... ${ }^{16}$ Los que interpretan majistralmente a los alemanes imprimen el cuño español en el oro del Rhin ... ${ }^{17} \mathrm{Si}$ refranes $\mathrm{i}$ cantos populares revelan el nacimiento de las literaturas, las composiciones alambicadas $i$ pequeñas dan indicios de agotamiento... ${ }^{18}$ Recapacitándolo con madurez, la buena prosa se reduce a conversación de jentes cultas ... ${ }^{19}$ Arcaísmo implica retroceso: a escritor arcaico, pensador retrógrado... ${ }^{20}$ quien no alza la voz en el certamen del Siglo, es porque nada tiene que decir. No arguyan con obstáculos insuperables: el hombre de talento sólido, como el César de buena raza, atraviesa el Rubicón." 21 De vez en cuando irrumpen los arrebatos $o$ invocaciones que indicamos en el esquema:

Acabemos ya el viaje milenario por rejiones de idealismo sin consistencia $\mathrm{i}$ regresemos al seno de la realidad, recordando que fuera de la Naturaleza no hai más que simbolismos ilusorios, fantasías mitolójicas, desvanecimientos metafísicos. A fuerza de ascender a cumbres enrarecidas, nos estamos volviendo vaporosos, aeriformes: i solidifiquémonos! Más vale ser hierro que nube. ${ }^{22}$

... Q Que nuestros poetas, en vez de pasar como interminable procesión de resuscitadas plañideras que se dirijen a la danza macabra, desfilen como lejiones de hombres que llevan en su corazón .el fuego de las pasiones fecundas...! ; Que nuestros prosadores, en lugar de afeminarse o enervarse con la prosa cortesana i enfermiza, usen la prosa leal $i$ sana . . ! 23 
...jOjalá nuestras sociedades científicas, literarias i artísticas se unieran para decir constantemente al Perú: Abre los ojos, deja la horrorosa pesadilla de sangre, porque el Siglo avanza con pasos jigantescos, i tiene mucho camino que recorrer, i mucha herida que restañar, $\mathrm{i}$ mucha ruina que reconstruir $\mathbf{2 4}$

Su ensayo "Nuestros ventrales" (1907) ${ }^{25}$ muestra forma parecida. El tema es la denuncia del materialismo peruano que se sobrepone a toda manifestación de la conciencia cívica. Mientras coma bien el peruano, "todo le duele menos de lo que había pensado." 26 Comienza Prada, a modo de ilustración, con dos incidentes históricos bien conocidos en el país: una azotaina pública recibida por un peruano a manos de los chilenos durante la ocupación después de la guerra, y la pública administración de un puntapié por el Presidente Castilla a un funcionario servil. Brotan luego numerosas metáforas, a veces gráficas, a veces aforísticas, que ejemplifican este servilismo y la gula: "Hasta se diría que las posaderas nacionales sienten la nostalgia del azote chileno... Nos hemos convertido en algo así como animales de espinazo horizontal... Vivimos en perpetuas bodas de Camacho. En las cinco partes del mundo no hay hombres más atareados que los marmitones de nuestros clubs $y$ de nuestros hoteles. Las quijadas de muchas gentes han resuelto el problema del movimiento continuo, los vientres de muchas personas han denunciado profundidades mayores que las del Océano Pacífico... Ese banquetear de Lima (digamos de una fracción limeña) ... es un escarmiento sangriento a los millares de infelices que tienen por único alimento un puñado de cancha $\mathrm{y}$ unas hojas secas .. . Lima es no sólo el gran receptáculo donde vienen a centralizarse las aguas sucias y las aguas limpias de los departamentos: es la immensa ventosa que chupa la sangre de toda la Nación... Hoy no se concibe la existencia de partidos ni la formación de oposiciones desinteresadas...; no se alían cerebros con cerebros, se juntan panzas con panzas." 27 Termina con una figura-resumen: "Asistimos a una zarabanda de pigmeos, a un desfile de mirmidones, a una pululación de Ventrales microscópicos." 28

"El honrado y el devoto" (1899), ${ }^{29}$ en cuanto a la forma, es un ejemplo típico de sus artículos periodísticos. Su tema -la honradez y la devoción religiosa no bastan para hacer buenos oficiales 
públicos (personificados en los presidentes Piérola y Romaña) - se ilustra al principio por una comparación:

El cajero que presenta un balance exacto, el notario que no falsifica documentos ni suprime expedientes, el síndico que religiosamente administra los bienes de la comunidad, el albañil que emplea buenos materiales y no cobra un céntimo más allá de lo pactado, el mandadero de monjas que hace todos los encargos sin sisar en el carbón ni en la leña, son personas muy honradas. ¿ Sirven, por ese único motizo, para embajadores, jueces, diputados, ministros o presidentes? 30

Hay aforisnos también: "La honradez política se resume en manejarse conforme a las convicciones que se profesan; así, a la mayor honradez política de un hombre corresponde mayor energía y constancia en profesar $y$ sostener sus ideas ... ${ }^{31}$ Un hombre muy honrado (entendiéndose por honradez la limpieza de manos) puede ser intolerante, despótico, inhumano, sanguinario." 32 Y termina Prada con una metáfora gráfica que simboliza a las dos figuras que ataca: "Si por un albañal figuramos el Gobierno de Piérola, debemos representarnos a Romaña como la tapa elegida para mantenerle herméticamente cerrado." 33

"Los milagros de un gobierno provisorio" (1914), ${ }^{34}$ a pesar de cubrir sólo una página y tener tres párrafos, ostenta la forma acostumbrada. Prada denuncia los alegados robos del dictador Benavides, comenzando con el siguiente pasaje metafórico:

No es necesario remontarse a los tiempos de Jesús para ver prodigios como la multiplicación de panes y peces. Los incrédulos no podrán negar que en una república, de cuyo nombre no queremos acordarnos, hay algo superior a la piedra filosofal de los alquimistas: en las libras y los soles, se nota el fenómeno de la generación espontánea; son granos de trigo que se convierten, por el transcurso de las horas, en espigas. 35

Dedica otra metáfora a la maniobra que llevó a Benavides al poder: "En Liliput, capital de la república de marras, se dió un sonado golpe de Estado el 15 de Mayo último." 36 Y como reiteración final de su ataque: "Ya sabemos la receta para hacer dinero". ${ }^{37}$

Ahora, a modo de resumen, puede hacerse una descripción somera, superficial, de su estilo. Tal descripción indicaría lo singular 
que era su prosa en la época. Propósito didáctico, exposición de nociones bastante sencillas de la moral, la sociología, etc. Frase y período generalmente cortos. Efecto espontáneo, dinámico, debido a arranques vehementes, a la abundancia de imágenes o metáforas inusitadas y a la presencia de aforismos y antítesis.

Aunque por insuficiencia de datos tenga que ser espectlativa, no queremos omitir aquí una consideración de las influencias que pueden haber contribuído a producir este estilo dinámico, de frase corta, concisa y propósito elocuente. Sabemos que Prada leyó y admiró mucho a autores conceptistas (Quevedo y Gracián) y a escritores modernos de frase corta como Bécquer, Renán y Guyau, etc. Conocía bastante bien a los parnasianos (y quizá menos a Flaubert), maestros de prosa cuidadosamente elaborada. Otra influencia posible, que no se debe olvidar, sería su intensa y variada lectura de periódicos y revistas franceses con sus artículos y polémicas de "style journaliste", calculado para influir sobre el público. Huelga inencionar su lectura de los prominentes escritores sociales de la época (marxistas, socialistas, anarquistas) que también ostentan un estilo persuasivo.

Imbuido como pocos escritores hispanoamericanos de su tiempo de la ciencia teórica y práctica, y de las ideas europeas contemporáneas, Prada ha querido producir, según su propia fórmula, una prosa que vive "al día, a la hora, al momento ..." 38

Sin embargo, al meditar esta estética pronto veremos cuán lejos está de expresar la verdad íntima del escritor. ${ }^{29}$ No es realmente una prosa llana, fluída, espontánea: todo lo contrario. Artística, sí: trabajada, calculada, esculpida; pero de una claridad intencionada, tan artificial como el foco de luz que arroja un proyector cinematográfico. ${ }^{40}$ No es que le sobren elementos a sus oraciones: elimina muchas preposiciones y artículos, pronombres y conjunciones relativas, y busca siempre la manera más concisa y eficaz en la exprestón. ${ }^{41}$ Como hemos visto, tiende a resumir sus ideas por medio de aforismos, frecuentemente metafóricos. Lo que le importa es transmitir la noción grabando su imagen con una figura deslumbradora pero siempre clara. Por tanto, escoge sus materiales cuidadosamente, limitándose como buen científico, al mínimo necesario. Prefiere frase corta, evita el lugar común en la expresión y economiza en los adjetivos, empleando el que considera justo, indispensable. Prada mis- 
mo observa: "El mérito de un adjetivo consiste en no admitir sustitución por adherirse al sustantivo, como la carne al hueso, como el tegumento al músculo." ${ }^{42} \mathrm{Y}$, revelando otro rasgo de su insistencia en la forma, recalca que la espontaneidad del estilo que recomienda es más aparente que real: "Los libros que admiran $\mathbf{i}$ deleitan a la Humanidad, fueron pensados i escritos en largas horas de soledad i recojimiento, costaron a sus autores el hierro de la sangre i el fósforo del cerebro." ${ }^{43}$ No se olvide, tampoco, el elemento lapidario en Prada: como ya notamos, nunca dejaba de corregir y mejorar sus propios textos. Así se comprenderá lo artificioso que sin duda hay en mucho de su efecto espontáneo.

No cabe duda que la estética de González Prada es nueva en la historia de la prosa hispana. Más bien racional y objetiva que subjetiva o poética, encierra a la vez la ventaja y desventaja de su prosa. Al ceñirse siempre a lo positivo, al insistir en que la ciencia, instrumento para resolver el complejo gris de la realidad, sólo da blanco y negro puros, gana su estilo en claridad y sus figuras se vuelven más plásticas. Al verter en ella la energía de sus hondas convicciones su prosa gana en dinamismo. ${ }^{44}$ Pero pronto el lector echa de ver en sus afirmaciones los matices e incertidumbres inevitables en la vida humana. En una palabra, simplifica demasiado la realidad. De aquí su talento para la caricatura; de aquí su singularidad entre la mayoría de los prosistas de su época; de aquí, también, la imposibilidad de llamarlo modernista pleno. Y de aquí, podríamos añadir, se comprende el crror, parcial cuando menos, de muchos críticos al llamarlo parnasiano. En sus procedimientos técnicos, en su insistencia en la perfección de forma, quizá lo fuera. Pero ¿cómo reconciliar con las teorías del parnaso el dinamismo, los "arranques enérgicos" que caracterizan su prosa, y su afirmación del fin didáctico de la literatura?

Las características nuevas de su estilo comenzaron a manifestarse en los mismos años de la aparición del modernismo. Fiel a su filosofía científica y propósito didáctico, predicaba la concisión y la claridad, rechazando tanto el efecto oratorio como la vaguedad sugestiva e intencionada del simbolismo. Fué uno de los primeros escritores hispanos en enriquecer la prosa no-técnica con aportes de las ciencias físicas y naturales y, en su propia patria, llegó a ser 
el definitivo introductor de las corrientes ideológicas de la Europa contemporánea. Su prosa, sin embargo, a pesar de sus claros valores renovadores, por razones cronológicas y teóricas, descontando algunos casos, no pudo influir marcadamente en los escritores de su época. Debido a la contemporaneidad y al auge del modernismo y a diferencias de teoría literaria, la mayor parte de sus innovaciones no cayeron en tierra fértil durante el período de Darío y Rodó. Además, fuera del Perú, Prada hubo de ser relativamente desconocido durante el modernismo. Había escrito poco (una parte considerable de su obra consistía en discursos y conferencias), usaba de seudónimos, $\mathrm{y}$ sus prosas no se reunieron en forma de libro hasta la publicación de Pájinas libres en 1894. Horas de lucha, su segundo libro, no apareció hasta 1908. Muchos de los temas tratados por Prada eran principalmente de interés a los peruanos $\mathrm{y}$, pecado mayor, iba contra la nueva corriente literaria que se había impuesto en la poesía, y ganaba terreno en el ensayo y la novela. Aun si la hubieran conocido todos los escritores de la época, su prosa no les habría influído salvo en casos excepcionales. Frente al estilo exótico, frágil y matizado que ganaba tantos partidarios para el modernismo, mucho menos habría simpatizado la actitud impersonal del peruano, ni sus metáforas científicas forjadas del "maravilloso positivo", ni su preocupación por los problemas sociales, ni su insistencia en la claridad diáfana, ni su persistente invectiva. Más les habría gustado su espíritu individualista, su voluntad de forma, st frase corta y su rechazo del retoricismo y la verbosidad. A los modernistas no les era difícil escaparse de la depresiva realidad mundana; para Prada, los ojos fijos en la escena peruana, esto era imposible.

En el Perú mismo, donde el modernismo no se desarrolló plenamente, su prosa influyó en algunos de los escritores jóvenes de c. 1900. Pueden citarse, como prueba de la eficacia de su ejemplo, las obras de los hermanos Francisco y Ventura García Calderón, Víctor Andrés Belaúnde y José de la Riva Agüero. Los cuatro principiaban su carrera por aquel entonces y todos han dejado testimonio, reconociendo la influencia de Prada. ${ }^{45} \mathrm{Y}$ esto a pesar de la poca simpatía que ellos sintieron por muchos de sus aspectos no literarios. Resume muy bien Ventura García Calderón la importancia de la prosa de González Prada al escribir que él "enseñó, el 
primero, el culto de la prosa armoniosa, cincelando el estilo, y a su ejemplo sin duda deben los nuevos [los prosistas de comienzos del 900] gran parte de su fervor." 46 Como se ve, esta influencia no se redujo a una imitación directa - cosa que el mismo Prada, enemigo de cenáculos y autoridades infalibles, nunca hubiera queridosino a un esfuerzo de parte del escritor para dejar la tradicional prosa castiza de la época y encontrar un estilo individual, de frase corta, ideas claras y expresión vigorosa.

Durante los últimos años de su vida el grupo "Colónida" ${ }^{47}$ (Abraham Valdelomar, Federico Guillermo Moore, Percy Gibson, José Carlos Mariátegui) rindió homenaje a Prada. Bajo la inspiración de Valdelomar, que desde Europạ había traído "gérmenes de d'annunzianismo", 48 los colónidas, "reclamaron sinceridad y naturalismo", protestando contra lo académico y conservador en literatura y tendiendo a un gusto decadente, elitista, aristocrático, algo mórbido." ${ }^{9}$ Demostraron a la yez un interés en el criollismo y un deseo de estrechar el contacto entre el escritor y el pueblo. Pero según uno de los mismos colónidas (José Carlos Mariátegui), la simpatía ideológica entre Prada y el grupo no fué completa. "Loaron y rodearon a González Prada... Amaron lo que en Prada había de aristócrata, de parnasiano, de individualista; ignoraban lo que en él había de agitador, de revolucionario..." 50 Y Luis Alberto Sánchez reitera esta noción al escirbir que el grupo "se colocó equidistantemente entre Palma [que vivía todavía] y González Prada. Es decir, entre la tradición limeña y la, insurrección de las provincias, entre el ayer apicarado y el mañana tonante." 51

Si el modernismo contribuyó a limitar la influencia del estilo nuevo que Prada desarrolló en su prosa, no sucedió así con las ideas que en ella se exponían. Además de estimular el decaído espíritu peruano durante los tres lustros de su actuación cívica y patriótica, la influencia de Prada se sintió en otras esferas intelectuales. El programa reformista que propuso en literatura, lingüística y ortografía suscitó una "polémica entre los gonzalezpradistas y los académicos [que] adquirió magnitudes de primera línea." $52 \mathrm{Y}$ en 1907 nota Francisco García Calderón que si en el Perú los intelectuales tuvieron poca influencia sobre el pensamiento nacional y si, por tanto, el positivismo no se había extendido grandemente, la influencia de González Prada sí fué sentida: algo en Lima, más 
en provincias. Lo compara a un "Vetullot librepenseur" y subraya la contribución de sus ideas laicas a la extensión de la indiferencia religiosa. ${ }^{53}$

En resumen, al aceptar el esquema que propone Alfonso Reyes de la aportación de los escritores americanos a la prosa española, ${ }^{54}$ sería justo reclamarle en él un lugar a Manuel González Prada, puesto que el escritor mexicano no menciona al gran prosista peruano. Como la de Sarmiento, su prosa es dinámica, "espoleada por 'el ritmo urgente del pensamiento,", y como la de Montalvo, "recuerda el tono de Quevedo, entonces insólito en España." En ella también, y a pesar de su didacticismo, aparece, como en la prosa de Martí y Gutiérrez Nájera, "la sentencia corta, eléctrica... y saltarina..." $5^{5}$ Como aportaciones enteramente suyas a la prosa pueden señalarse un estilo combativo caracterizado por un tono agresivo rara vez igualado en español $y$, reflejo de sus extensas lecturas científicas, un talento para forjar caricaturas y metáforas de términos antes inusitados en la prosa española.

Robert G. Mfad, JR., The University of Connecticut, Storrs, Connecticut.

\section{$\mathrm{NOTAS}$}

1 Su último libro de prosa, El tonel de Diógenes, (México, Edit. Tezontle), se publicó en 1945. La casa editora limeña P. T. C. M. en 1946 comenzó la publicación de sus Obras completas, con el texto definitivo del autor. Entre las más recientes apreciaciones de Prada pueden señalarse los artículos inclúdos en el Repertorio americano del 12 de junio de 1948; y las referencias en "Panorama de la literatura peruana", por' Abraham Arias larreta en la Revista iberoamericana, xIv, (1948), 97-102; Memorias, (Lima, Edit. Rimac, 1947) por Rafael Larco Herrera, págs. 19-21; The epic of Latin America, (New York, Doubleday, 1946) por John A. Crow, págs. 634-637; Redes para captar la mube, (Lima, Edit. P. T. C. M., 1946) por Alfredo González Prada, págs. 202, 238-239, 243-253; "Introducción a Pájinas libres, (Lima, Edit. P. T. C. M., 1946) por Luis Alberto Sánchez, págs. v-x; Jwventud de América, (México, "Cuadernos Americanos", 1946) por Gregorio Bermann, págs. 154-155; Literary Currents in Hispanic Anerica, (Cambridge, Harvard University Press, 1945) por Pedro Henríquez-Ureña, págs. 154-155 y passim; 
Del ensayo americano, (México, Fondo de cultura económica, 1945) por Medardo Vitier, págs. 173-174; A Century of Latin American Thought, (Cambridge, Harvard University Press, 1944) por William Rex Crawford, págs. 173-182; La literatura del Peru, (Buenos Aires, Imprenta de la Universidad, 1943) por Luis Alberto Sánchez, págs. 111, 121-130 y passim; “González Prada: profeta y poeta", por Luis Velazco Aragón en la Revista iberoamericana, vis, (1943), 21-37.

2 Las antologías de la prosa son Gonzáles Prada. New York, Instituto de las Españas en los Estados Unidos, 1938; Pensamientos. Buenos Aires, Arco Iris, 1941; Gonsález Prada. México, Secretaría de Educación Pública, 1943; Manuel Gonsáles Prada. México, Imprenta universitaria, 1945; la antología poética la publicó el Instituto Internacional de Literatura Iberoamericana como el primer volumen de los Clásicos de Amórica. México, Editorial Cultura, 1940.

3 Rufino Blanco-Fombona dedica unas cuantas páginas a la prosa de Prada en su estudio crítico inclúdo en Figuras y figurones, (París, Edit. Bellenand, 1948) por Manuel González Prada, y Jorge Mañach insertó un corto pero sugestivo esquisse sobre el mismo tema en la Revista hispánica noderna, Iv, (1938), 18-23.

4 Empleanos, en cuanto a las generaciones literarias, la terminologia propuesta por Pedro Henríquez-Ureña. Véase Enrique Anderson-Imbert, "Un juicio póstumo de Pedro Henríquez-Ureña sobre las generaciones literarias", Realidod, IV, (1948), 354-356.

5 Enrique Anderson-Imbert, El arte en la prosa de Juan Montalvo. México, El Colegio de México, 1948, págs. 92-93.

6 Ibid., págs. 92-102.

7 Manuel González Prada, Pájinas libres. Lima, Edit. P. T. C. M., 1946, p. 229. Reproducimos en esta cita (y en las siguientes que se hacen de este libro) la ortografía que Prada empleaba en aquel entonces.

8 Ibid., p. 21.

9 Medardo Vitier, Del ensayo americano, págs. 53, 76.

10 Ibid., p. 46.

11 Características de los escritos en Páfinas libres, (primera edición, 1894) y Horas de lucha, (primera edición, 1908).

12 La mayor parte de su obra periodística está en Anarquía, Propaganda y ataque y Prosa memuda.

13 Véanse los ensayos de su última década incluídos en Nuevas páginas libres y El tonel de Diógenes.

14 Pájinas libres, págs. 3-32. 
15. Ibid., p. 3.

16 Ibid., p. 11.

17 Ibid., p. 16.

18 Ibid., p. 18.

19 Ibid., p. 21.

20 Ibid.

21 Ibid., p. 32.

22 Ibid., págs. 26-27.

23 Ibid., p. 28.

24 Ibid., p. 32. La conferencia termina con la invocación que citamos.

25 Horas de lucha. Buenos Aires, Edit. Americalee, 1946, págs. 154-160.

26 Ibid.; p. 155.

27 Ibid., págs. 155-160.

28 Ibid., p. 160.

29 Propaganda y ataque. Buenos Aires, Edit. Imán, 1939, págs. 143-148.

30 Ibid., págs. 144-145.

31 Ibid., p. 144.

32 Ibid., p. 145.

33 Ibid., p. 148.

34 Prosa menuda. Buenos Aires, Edit. Imán, 1941, págs. 227-228.

35 Ibid., p. 227.

36 Ibid.

37 Ibid., p. 228.

38 Pájinas libres, p. 21.

39 Es interesante observar que Alfredo González Prada, hijo de don Manuel, también considera que el estilo de su padre como prosador no está en consonancia con sus ideales más intimos de artista literario:

"Cuando González-Prada apareció ante los ojos del descorazonado Perú de 1885, traía el anhelo de 'dominar a las muchedumbres', de infundirles una nuteva energía, de animarles en una fresca esperanza. $\mathrm{Y}$ para galvanizar el entusiasmo de los amilanados y de los apáticos, se arrojó a la lucha, izanido al tope de sus mástiles, 'las figuras de relumbrón.' Pero escondía González- 
Prada delicadezas de artífice y refinamientos de aristócrata ingénitamente en riña con la deliberada altisonancia de ciertos instantes de su estilo. Hacía uso de una manera que, por temperamento, no le era propia. Que la aplicó con maestría, to atestigua la eficacia de su obra y la solidez de su fama; que la empleó con repugnancia, lo prueba una faz más libre y espontánea de su personalidad: el poeta". [A1fredo González Prada; Redes para captar la nube, págs. 202-204.]

40 Luis Alberto Sánchez escribe: "...Prada nunca se sintió contento de su obra excelsa. Trabajó incesantemente en mejorar sus propios textos." [Introducción a Pájinas libres, p. Ix]. Su hijo al redactar los textos inéditos de Prada comenta las numerosas revisiones y notas marginales del attor, algunas hechas muchos años después de la composición original.

41 Destácase, en su teoría del lenguaje, el deseo de eliminar muchos ganchos sintácticos: "La frase pierde algo de su virilidad con la superabundancia de artículos, pronombres, preposiciones i conjunciones relativas." Rechaza el abuso de el, la, los, las, él, ella, quien, el (la) cual, etc., y đle que, de, cuyo, cuya. [Pájinas libres, p. 269.] El lector atento nota pronto la relativa escasez de estas voces en la prosa de González Prada.

42 Pájinas libres, p. 237.

43 Ibid., p. 20.

44 Nadie menos que don Miguel de Unamuno atestigua la novedad y la eficacia de esta prosa dinámica: “... conozco pocos autores, americanos y no americanos, que remuevan más que Prada el espíritu de los que lo leen... González Prada es lo que llaman por aqui un escritor vibrante, es un escritor de lucha, un incansable forjador de metáforas, un hombre que escribe a estocadas retóricas." [Miguel de Unamuno, Ensayos. Madrid, Edit. Residencia de estudiantes, 1918, vir, 115].

45 Véanse Francisco García Calderón, Le Pérou contemporain. París, Edit. Dujarric, 1907, págs. 115, 202-203; Ventura García Calderón, Del romanticismo al modernismo. París, Edit. Ollendorff, 1910, págs. xı, 399; José de la Riva Agüero, Carácter de la literatura del Perú independiente. Lima, Edit. Rosay, 1905, p. 192; Víctor Andrés Belaúnde, "González Prada, escritor de combate", Mercurio peruano, I, (1918), 65-69.

46 Ventura García Calderón, loc. cit.

47 Designación tomada del nombre de la revista Colónida fundada por Valdelomar.

48 José Carlos Mariátegui, Siete ensayos de interpretación de la realidad peruana. Lina, Edit. Minerva, 1944, p. 218.

49 Ibid.

50 Ibid., p. 219. 
51 Luis Alberto Sánchez, La literatura del Perú, p. 155.

52 Ibid., p. 139.

53 Francisco García Calderón, loc, cit.

54 Alfonso Reyes, Pasado inmediato y otros ensayos. México, E1 Colegio de México, 1941, págs. 68-69.

55 Ibid. 